\title{
In vitro expression of HPV16 E7 linked to HMGB1 immunoadjuvant in mammalian cells
}

\author{
Talebi S ${ }^{1}$, Bolhassani A², Mokhtari Azad T², Arashkia A4 ${ }^{4}$, Modaresi $\mathrm{MH}^{5}$ \\ Department of Biology, Science and Research Branch, Islamic Azad University, Tehran, Iran. \\ azam.bolhassani@yahoo.com
}

\begin{abstract}
BACKGROUND: E7 is the major transforming protein of human papillomavirus (HPV) that plays important role in maintaining the proliferative state in HPV-infected cells. Furthermore, high mobility group 1 protein (HMGB1) is a highly conserved component of chromatin that can be secreted by macrophages and activated monocytes and thus functions as an inflammation mediator.

METHODS: In the current study, cloning of HMGB1 gene and also HPV16E7-HMGB1 was performed in pEGFP-N1 eukaryotic expression vector in order to evaluate their expression in mammalian cells. For this purpose, the HEK-293T cells were transfected by pEGFP-E7, pEGFP-HMGB1 and pEGFP-E7-HMGB1 using TurboFect delivery system. The levels of protein expression were assessed by flow cytometry and fluorescent microscopy at $48 \mathrm{hr}$ after transfection, as well as by western blot analysis using anti-GFP polyclonal antibody.

RESULTS: Our data showed a clear band of $\sim 684$ bp and $\sim 981$ bp related to HMGB1 and E7-HMGB1 genes in agarose gel, respectively. The expression of HMGB1-GFP and E7-HMGB1-GFP proteins was confirmed for the bands of $\sim 53 \mathrm{kDa}$ and $\sim 64 \mathrm{kDa}$ in the transfected cells using western blot analysis, respectively. The linkage of HMGB1 gene to E7 could likely neutralize the negative charges of E7, thus a clear band of $64 \mathrm{kDa}$ was detected instead of $76 \mathrm{kDa}$ in western blot analysis. Moreover, the percentage of expression for E7-GFP, HMGB1-GFP and E7-HMGB1-GFP was $76 \%, 55 \%$, and $52 \%$, in comparison with pEGFP-N1 ( 82 \%) as a positive control. Indeed, HMGB1 linked to HPV16 E7 gene decreased transfection efficiency of E7 DNA in HEK-293T cells. CONCLUSION: Generally, the electrophoretic mobility of HPV16 E7 was changed due to the linkage of HMGB1 gene. Furthermore, the fusion protein could be efficiently expressed in mammalian cells for the next use in immunotherapy (Fig. 3, Ref. 51). Text in PDF www.elis.sk.

KEY WORDS: high mobility group box 1, HEK-293T, pEGFP-N1, cell transfection.
\end{abstract}

\section{Introduction}

Human papillomaviruses (HPVs) are responsible for malignant tumor formation in genital regions (e.g., high-risk or oncogenic HPVs), as well as benign anogenital warts (e.g., low risk or non-oncogenic HPVs) (1-3). Among the main genotypes of high-risk HPVs, HPV-16 is the most common genotype and responsible for $\sim 60 \%$ of cervical cancer cases in the world (3-7). The studies showed that E6 and E7 oncoproteins expressed in the early stages of HPV infection maintain the proliferative state in HPV-infected cells (8-10). HPV16 E7 is a small protein with a natively unfolded domain that is constitutively expressed in all layers of the infected epithelium. According to the reports,

${ }^{1}$ Department of Biology, Science and Research Branch, Islamic Azad University, Tehran, Iran, ${ }^{2}$ Department of Hepatitis and AIDS, Pasteur Institute of Iran, Tehran, Iran, ${ }^{3}$ Department of Virology, School of Public Health, Tehran University of Medical Sciences (TUMS), Tehran, Iran, ${ }^{4}$ Department of Virology, Pasteur Institute of Iran, Tehran, Iran, and ${ }^{5}$ Department of Medical Genetics, Faculty of Medicine, Tehran University of Medicine Science, Tehran, Iran

Address for correspondence: A. Bolhassani, PhD, Department of Hepatitis and AIDs, Pasteur Institute of Iran, Tehran, Iran.

Phone: +98.21.66953311/2240, Fax: +98.21.66465132 the E7-specific T-cell responses could provide protection against the growth of a transformed tumor cell line. Thus, E7 protein is considered as a tumor antigen for development of immunotherapy (11-19). Among different therapeutic vaccines, DNA vaccines have been widely used to develop vaccines against various infectious diseases and cancer. Recently, several strategies have been applied to increase the potency of DNA vaccine such as the use of adjuvants, and delivery systems (20). High mobility group protein B1 (HMGB1) is a highly conserved nuclear protein that was proposed as a novel effective adjuvant in DNA vaccination against a lethal mucosal influenza A/PR/8/34 challenge. Indeed, HMGB1 adjuvant is able to enhance adaptive effector and memory immune responses (21). HMGB1 acts as a multi-functional protein and an extracellular signaling molecule during recombination, transcriptional regulation, inflammation, cell differentiation, cell migration, and tumor metastasis (22-26). Due to its role in inflammation, HMGB1 was used for treatment of rheumatoid arthritis and also sepsis $(27,28)$. HMGB1 can facilitate the binding of p53 to DNA using the DNA bending (29-34). In the current study, we constructed the DNA encoding HMGB1 gene as well as the E7-HMGB1 fusion and evaluated their expression in a human cell line using fluorescent microscopy, flow cytometry, and western blotting. 
$609-613$

\section{Materials and Methods}

\section{Construction of pEGFP-HMGB1 and pEGFP-E7-HMGB1}

The full length of HMGB1 gene (Access No: NM_010439) was obtained from the pBluescript II SK+ vector containing the coding sequence of HMGB1 protein (Synthesized by BioMatik co., Canada). For preparation of pEGFP-HMGB1 and also pEGFP-E7HMGB1 constructs, the HMGB1 gene ( $684 \mathrm{bp})$ was cloned into the KpnI /Age I sites of pEGFP-N1 (Clontech, Palo Alto, CA, USA) and pEGFP-E7 (previously provided by Bolhassani et al., 35), respectively. The forward and reverse primers for amplifying the HMGB1 (HMG-F \& HMG-R) were designed as follows (the enzyme restriction sites are shown in bold).

HMG-F: 5' AGG TAC CGA GGG ATC CAT GGG CAA A 3' HMG-R: 5' AAC CGG TAATTC TTC TTCATC TTC GTC TTC C 3'

PCR analysis was performed by PCR thermal cycler under standard conditions $\left(94^{\circ} \mathrm{C}\right.$ for $1 \mathrm{~min} ; 55^{\circ} \mathrm{C}$ for $45 \mathrm{~s}$ and $72^{\circ} \mathrm{C}$ for $1 \mathrm{~min} ; 30$ cycles) and the product was separated on a 0.8 percent agarose gel. The bands corresponding to the expected PCR products size were gel purified (QIAquick gel extraction kit protocol, QIAGEN), digested with KpnI and AgeI, and ligated into a similarly digested expression vectors (pEGFP-N1 \& pEGFP-E7) using T4 DNA ligase (Fermentas, Germany). The ligation mixtures were used to transform E. coli DH5 $\alpha$ strains. The plasmid DNAs were purified from recombinant clones by an alkaline lysis method. The presence of the inserted HMGB1 fragment was confirmed by PCR and restriction enzyme digestion as detected on gel electrophoresis and finally sequenced using the dideoxy chain termination method on an automated sequencer. DNA constructs containing HMGB1 (pEGFP-HMGB1 and pEGFP-E7-HMGB1) were purified in large-scale using Midi-kit (Qiagen). DNA concentrations were determined by the absorbance measured at $260 \mathrm{~nm}$.
In vitro expression of HMGB1, and E7-HMGB1 proteins in HEK293 T cells

Human HEK-293 T cells (provided from the cell bank of Pasteur Institute of Iran) were maintained in complete RPMI (Sigma) medium supplemented with $10 \%$ fetal calf serum (FCS, Gibco) at $37^{\circ} \mathrm{C}$ and $5 \% \mathrm{CO}_{2}$ atmosphere. Then, the cells were seeded into a 12-well plate and transfected using TurboFect as in vitro delivery reagent. For DNA transfection with TurboFect (cationic polymer, Fermentas), the recombinant pEGFP-HMGB1 and pEGFP-E7-HMGB1 vectors $(\sim 1-2 \mu \mathrm{g})$ were pre-incubated with $4 \mu \mathrm{l}$ of reagent in a final volume of $25 \mu 1$ and incubated at room temperature for $20 \mathrm{~min}$ to form the DNA/TurboFect complexes. The complexes were then added to each well containing cells and medium. Cells were harvested $48 \mathrm{~h}$ post-transfection, washed, and re-suspended in PBS, to determine the proportion of fluorescent cells expressing HMGB1 or E7-HMGB1 proteins using flow cytometry. The quality of protein expression was also detected by fluorescent microscopy and western blotting. The pEGFP-N1 was used as a positive control.

\section{Western blot analysis}

HEK-293 T cells were washed with PBS and lysed in wholecell lysis buffer (10\% glycerol, 0.5 mM EDTA, 1 mM DTT, $2 \mathrm{mM}$ natrium fluoride, $0.2 \%$ Triton $\mathrm{X}-100$ in $\mathrm{PBS} \mathrm{pH}=7.4$ ) supplemented with protease inhibitor (Sigma). Proteins were separated on $12.5 \%$ (w/v) polyacrylamide gel and transferred to nitrocellulose membrane (Millipore). The anti-GFP polyclonal antibody (Acris, USA, 1:10000 v/v) was used to confirm HMGB1-GFP, E7-HMGB1-GFP protein expression under standard procedures. The immunoreactive protein bands were visualized using peroxidase substrate named 3, 3'-diaminobenzidine (DAB, Sigma).
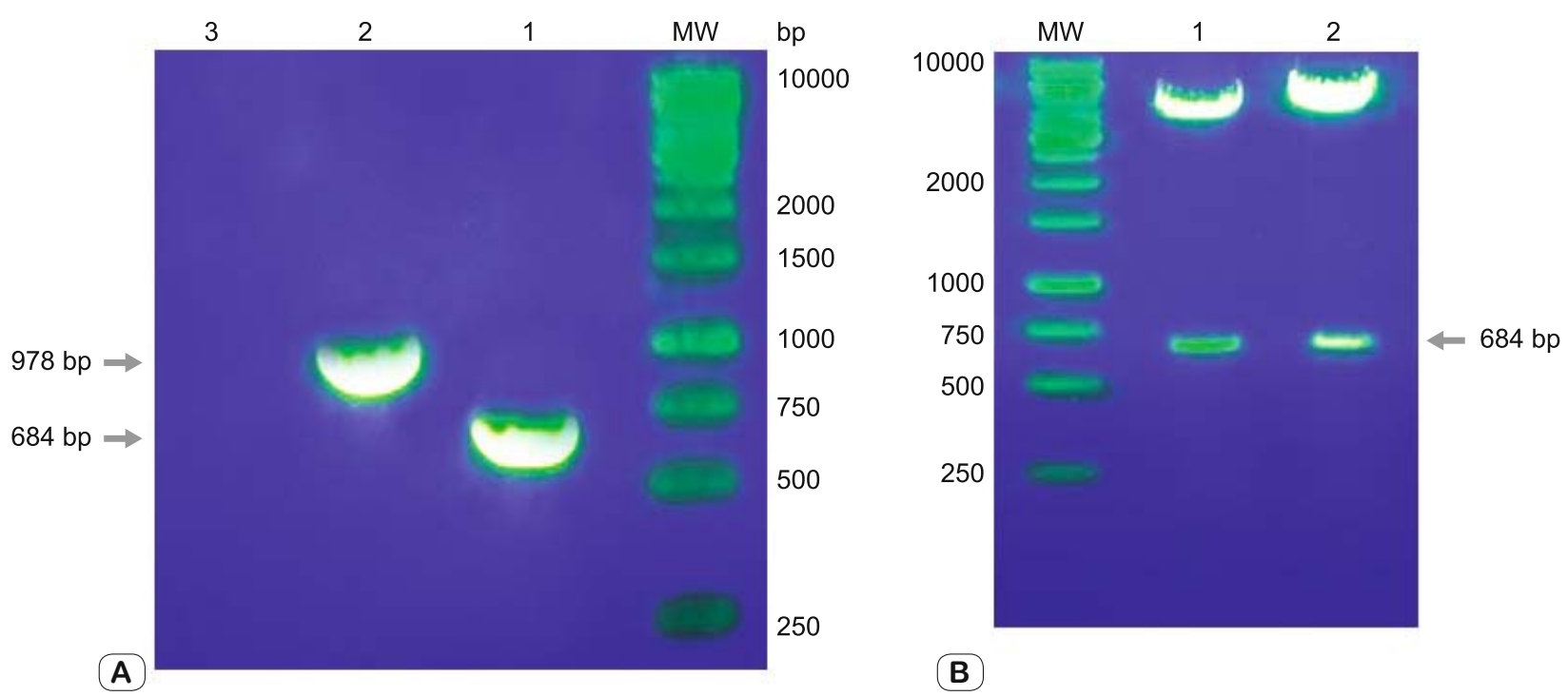

B

Fig. 1. Cloning of HMGB1 into the multiple cloning sites (MCS) of pEGFP and pEGFP-E7 vectors: A) PCR analysis of HMGB1 (lane 1, 684 bp) and E7-HMGB1 (lane 2, 978 bp) from pEGFP-HMGB1 and pEGFP-E7-HMGB1 vectors, respectively. B) The confirmation of $H M G B 1$ gene ( 684 bp) by digestion from pEGFP-HMGB1 vector (lane 1), and pEGFP-E7-HMGB1 vectors (lane 2); MW is molecular weight marker (Fermentas, Germany). 

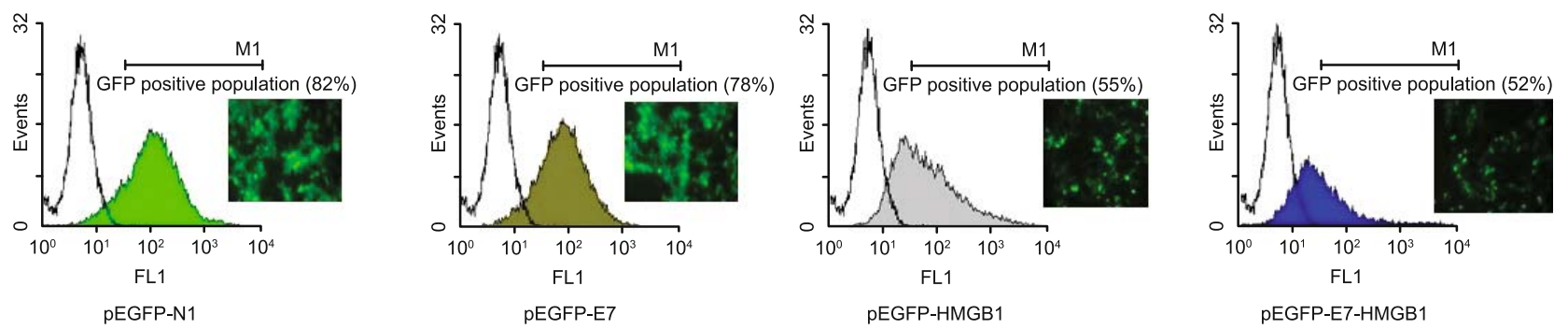

Fig. 2. Expression analysis of GFP, E7-GFP, HMGB1-GFP and E7-HMGB1-GFP proteins in HEK-293T cells transfected by pEGFP-N1 (A), pEGFP-E7 (B), pEGFP-HMGB1 (C), and pEGFP-E7-HMGB1 (D) using flow cytometry and fluorescent microscopy.

\section{Statistical analysis}

Statistical analysis (Student's t-test) was performed by Prism 5.0 software (GraphPad, San Diego, California, USA) to analyze the percentage of HMGB1-GFP, and E7-HMGB1-GFP expression using flow cytometry. The value of $p<0.05$ was considered statistically significant. Similar results were obtained in two independent experiments.

\section{Results}

\section{Generation of HMGB1 and E7-HMGB1 DNA constructs}

At first, the HMGB1 gene was inserted into the N-terminal of pEGFP-N1 and pEGFP-E7 expression vectors without stop codon for construction of pEGFP-HMGB1 and pEGFP-E7-HMGB1. The recombinant plasmids as well as pEGFP-N1 were prepared in large scale and confirmed by PCR and digestion. The results showed that HMGB1 and E7-HMGB1 migrated as the clear bands of $\sim 684$, and 978 bp in agarose gel, respectively (Figure 1).

HMGB1 linked to HPV16 E7 gene decreased transfection efficiency of E7 DNA in HEK-293T cells

In vitro DNA delivery of HMGB1 and E7-HMGB1 was performed by TurboFect as the transfection reagent. GFP expression was evaluated by fluorescence microscopy and flow cytometry at $48 \mathrm{~h}$ after transfecting HEK-293T cells. GFP fluorescence was observed in the cells that received 1-2 $\mu \mathrm{g}$ of pEGFP-N1, pEGFP-E7, pEGFP-HMGB1, and pEGFP-E7-HMGB1 vectors. The levels of protein expression were $82 \%$ for $\mathrm{pEGFP-N1} ; 78 \%$ for $\mathrm{pEGFP}-\mathrm{E} 7$; $55 \%$ for pEGFP-HMGB1, and 52\% for pEGFP-E7-HMGB1 using TurboFect reagent. The level of GFP expression detected by pEGFP-E7 delivery was significantly higher than that by pEGFPHMGB1 and pEGFP-E7-HMGB1 transfection $(p<0.05$, Figure 2). The efficiencies of HMGB1 and E7-HMGB1 gene expression were similar at $48 \mathrm{~h}$ after cell transfection.

Identification of HMGB1 and E7-HMGB1 gene expression using western blot analysis

Western blot analysis was performed using anti-GFP polyclonal antibody to ensure the proper expression of HMGB1 and E7HMGB1 proteins. The specific bands with expected size of $53 \mathrm{kDa}$, and $64 \mathrm{kDa}$ were detected for HMGB1-GFP, and E7-HMGB1-GFP expressed from $\mathrm{pEGFP-HMGB1}$, and $\mathrm{pEGFP-E7-HMGB1}$ vectors

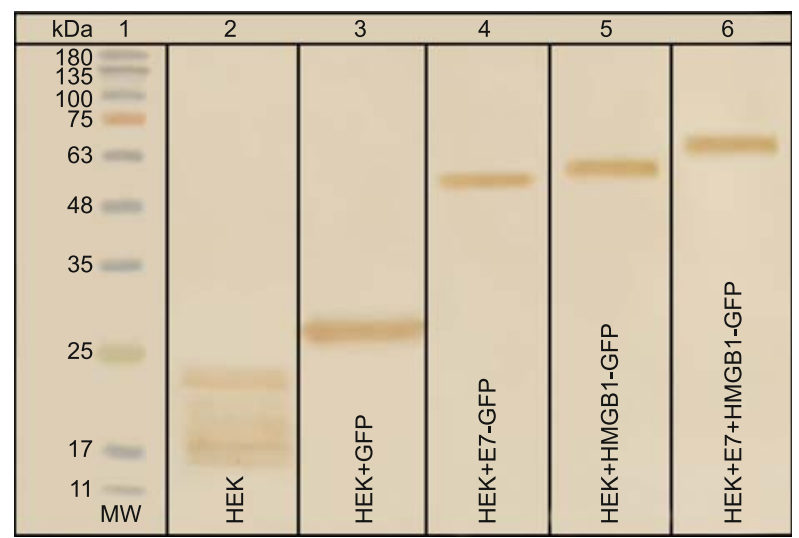

Fig. 3. Western blot analysis using an anti-GFP antibody: The results showed the expression of the full-length GFP (lane 3, $27 \mathrm{kDa}$ ), E7GFP (lane 4, $50 \mathrm{kDa}$ ), HMGB1-GFP (lane 5, $53 \mathrm{kDa}$ ), and E7HMGB1-GFP (lane 6, $64 \mathrm{kDa}$ ) proteins. A detectable band was not observed in untransfected cells (lane 2 ) as a negative control. MW is molecular weight marker (lane 1, Fermentas).

in the transfected cells, respectively as shown in Figure 3. Indeed, HMGB1 or E7-HMGB1 expression was detectable in transfected cells as compared to untransfected cell extracts by western blotting. The results showed that the linkage of HMGB1 gene to E7 could likely neutralize the negative charges of E7, thus a clear band of $64 \mathrm{kDa}$ was detected instead of $76 \mathrm{kDa}$ in western blot analysis.

\section{Discussion}

HPV 16 is the most important HPV type which can be detected in about half of all invasive cervical cancers (36). Great efforts are recently undertaken to develop therapeutic vaccines against HPV infections. HPV E7 protein is expressed in all tumor tissues and used as an effective antigen in vaccine design $(37,38)$. In the current study, the expression of E7, HMGB1 and E7-HMGB1 in human cell line was evaluated and compared by both western blotting and flow cytometry. In order to achieve these goals, the HMGB1 ( 684 bp) and E7-HMGB1 ( 978 bp) genes were cloned into eukaryotic expression vector ( $\mathrm{pEGFP-N1)}$. The correct cloning was confirmed by digestion and PCR analysis. Then, HEK-293T cells were transfected by the purified plasmid DNAs using TurboFect reagent. As known, transfection is a powerful analytical tool that delivers for- 
eign nucleic acids into cells to generate genetically modified cells. The transfection methods are classified into three groups such as biological, chemical, and physical delivery systems (39). Herein, we used a cationic polymer (TurboFect) for DNA delivery. Western blotting is a widely used technique for the detection and analysis of proteins based on their ability to bind to specific antibodies (4042). In this study, anti-GFP antibody was used to bind GFP fused to proteins of interest. Western blot analysis showed the presence of the prominent protein bands related to HMGB1 andE7-HMGB1 that were not detectable in un-transfected cell lysates. In the presence of sodium dodecyl sulphate (SDS) and 2-mercaptoethanol (2-ME), the E7-GFP protein migrated as a $50 \mathrm{kDa}$ protein $(23 \mathrm{kDa}$ $\mathrm{E} 7+27 \mathrm{kDa}$ GFP) during poly acrylamide gel electrophoresis. The theoretical molecular mass of E7 protein is nearly $11 \mathrm{kDa}$. The previous data indicated that the substantial net negative charge of the wild type E7 protein is responsible for its anomalous electrophoretic behavior. This electrophoretic behaviour of the HPV16E7 protein was associated with the amino terminal half of the protein $(43,44)$. Our findings indicated that the linkage of HMGB1 to E7 decreased protein size from $\sim 76 \mathrm{kDa}(23 \mathrm{kDa}$ E7+ $25 \mathrm{kDaHMGB} 1+$ $27 \mathrm{kDa}$ GFP) to $\sim 64 \mathrm{kDa}(11 \mathrm{kDa}$ E7+ $25 \mathrm{kDa} \mathrm{HMGB} 1+27 \mathrm{kDa}$ GFP) in western blot analysis. Indeed, the HMGB1 likely led to charge neutralization and protein migration in normal size. In addition, the cell expression of HMGB1 and E7-HMGB1 was similar and significantly lower than E7 protein. This result showed lower uptake of HMGB1 and also E7-HMGB1 as compared to E7 protein in HEK-293T cells. Fluorescence microscopy as an efficient and unique tool also showed DNAs transport and their expression to living cells because of its specificity, and high sensitivity. The studies indicated that fluorescence microscope can detect the fluorescence emitted from labeled molecules in biological samples as images or photometric data from which intensities and emission spectra can be deduced $(45,46)$. Generally, the expression systems utilizing mammalian cells are able to generate recombinant proteins with proper folding, post-translational modifications which are important for their biological activity. Up to now, a number of mammalian cell lines have been used for protein expression including HEK-293 (Human embryonic kidney) and CHO (Chinese hamster ovary). HEK-293 cells exhibited the highest level of polyethyleneimine(PEI)-mediated transfection for GFP expression ( $~ 50-80 \%$ of cells), and were widely used for production of recombinant proteins both by transient transfection as well as by the formation of stable cell lines (47). Our data also represented high efficiency of HEK$293 \mathrm{~T}$ for GFP expression using Turbofect $(\sim 82 \%)$ as well as high expression of the E7 ( 76\%), HMGB1 ( 55\%), and E7-HMGB1 $(\sim 52 \%)$ proteins using flow cytometry analysis. Flow cytometry technique provides qualitative and quantitative analysis of single cells using fluorescent markers such as GFP (48-50). GFP reporter gene is a useful approach for evaluation of gene expression (51) as observed in our study.

\section{Conclusion}

In summary, the recombinant HMGB1 and E7-HMGB1 plasmids could be delivered into HEK-293T cells using TurboFect cationic polymer and efficiently expressed in vitro. Regarding the suitable expression of DNA constructs, they will be used for in vivo studies as a therapeutic DNA vaccine in future.

\section{References}

1. Bernard HU, Burk RD, Chen Z, van Doorslaer K, zur Hausen H, de Villiers EM. Classification of papillomaviruses (PVs) based on $189 \mathrm{PV}$ types and proposal of taxonomic amendments. Virology 2010; 401: 70-79.

2. Horvath CAJ, Boulet GAV, Renoux VM, Delvenne PO, Bogers JPJ. Mechanisms cell entry by human papillomaviruses: an overview. Virology J 2010; 7 (11): 1-7.

3. Walboomers JM, Jacobs MV, Manos MM, Bosch FX, Kummer JA, Shah KV, Snijders PJ, Peto J, Meijer CJ, Muñoz N. Human papillomavirus is a necessary cause of invasive cervical cancer worldwide. J Pathol 1999; 189 (1): 9-12.

4. Muñoz N, Bosch FX, de Sanjosé S, Herrero R, Castellsagué X, Shah KV, Snijders PJ, Meijer CJ. Epidemiologic classification of human papillomavirus types associated with cervical cancer. N Engl J Med 2003; 348: 518-527.

5. Munoz N, Castellsague X, de Gonzalez AB, Gissmann L. Chapter1: HPV in the etiology of human cancer. Vaccine 2006; 24: S3/1-S3/10.

6. Dürst M, Gissmann L, Ikenberg $\mathbf{H}$, zur Hausen $H$. A papillomavirus DNA from a cervical carcinoma and its prevalence in cancer biopsy samples from different geographic regions. Proc Natl Acad Sci USA 1983; 80: 3812-3815.

7. Zheng ZM. Viral oncogenes noncoding RNAs, and RNA splicing in human tumor viruses. Int J Biol Sci 2010; 6: 730-755.

8. Werness BA, Levine AJ, Howley PM. Association of human papillomavirus types 16 and 18 E6 proteins with p53. Science 1990; 248 (4951): 76-79.

9. zur Hausen H. Papillomaviruses and cancer: from basic studies to clinical application. Nat Rev Cancer 2002; 2 (5): 342-350.

10. Hu Z, Ding W, Zhu D, Yu L, Jiang X, Wang X, Zhang C, Wang L, He D, Xia X, Zhu T, Wei J, Wu P, Wang C, Xi L, Gao Q, Chen G, Li S, Wang S, Zhou J, Ma D, Wang H, Ji T, Liu R, Liu D, Li K. TALENmediated targeting of HPV oncogenes ameliorates HPV-related cervical malignancy. JCI 2015; 125 (1): 425-436.

11. Munger K, Phelps WC, Bubb V, Howley PM, Schlegel R. The E6 and E7 genes of the human papillomavirus type 16 together are necessary and sufficient for transformation of primary human keratinocytes. J Virol 1989; 63: 4417-4421

12. Boyer SN, Wazer DE, Band V. E7 protein of human papillomavirus 16 induces degradation of retinoblastoma protein through the ubiquitin-proteasome pathway. Cancer Res 1996; 56: 4620-4624.

13. Kalejta RF. Human cytomegalovirus pp71: a new viral tool to probe the mechanisms of cell cycle progression and oncogenesis controlled by the retinoblastoma family of tumor suppressors. J Cell Biochem 2004; 93: 37-45.

14. Dantur K, Alonso L, Casta E, Morelli L, Centeno-Crowley JM, Vighi S, de Prat-Gay G. Cytosolic accumulation of HPV16 E7 oligomers supports different transformation routes for the prototypic viral oncoprotein: The amyloid-cancer connection. Int J Cancer 2009; 125: 1902-1911.

15. Tahamtan A, Ghaemi A, Gorji A, Kalhor HR, Sajadian A, Moradi A, Atyabi F, Kelishadi M. Antitumor effect of therapeutic HPV DNA vaccines with chitosan-based nanodelivery systems. J Biomed Sci 2014; 21 (1): 69. 
16. Panda AK. Bioprocessing of therapeutic proteins from the inclusion bodies of Escherichia coli. Adv Biochem Eng Biotechnol 2003; 85: 43-93.

17. Chen LP, Thomas EK, Hu SL, Hellstrom I, Hellstrom KE. Human papillomavirus type 16 nucleoprotein E7 is a tumor rejection antigen. Proc Natl Acad Sci USA 1991; 88: 110-114.

18. Bian T, Zhao L, Ruan L, Wang Y, Ren J, Lu Z, Zhang H, Tian H. Human papillomavirus type 16 L1E7 chimeric capsomeres have prophylactic and therapeutic efficacy against papillomavirus in mice. Mol Cancer Ther 2008; 7 (5): 1329-1335.

19. Ajiro M, Zheng ZM. E6 $6^{\wedge} \mathrm{E} 7$, a novel splice isoform protein of human papillomavirus 16, stabilizes viral E6 and E7 oncoproteins via HSP90 and GRP78. MBio 2015; 6 (1): e02068-14

20. Bolhassani A, Rafati S. DNA immunization as an efficient strategy for vaccination. Avicenna J Med Biotech 2009; 1 (2): 71-88.

21. Fagone P, Shedlock DJ, Bao H, Kawalekar OU, Yan J, Gupta D, Morrow MP, Patel A, Kobinger GP, Muthumani K, Weiner DB. Molecular adjuvant HMGB1 enhances anti-influenza immunity during DNA vaccination. Gene Ther 2011; 18 (11): 1070-1077.

22. Swanson PC. Fine structure and activity of discrete RAG-HMG complexes on V(D)J recombination signals. Mol Cell Biol 2002; 22: 1340-1351.

23. Boonyaratanakornkit V, Melvin V, Prendergast P, Altmann M, Ronfani L, Bianchi ME, Taraseviciene L, Nordeen SK, Allegretto EA, Edwards DP. High-mobility group chromatin proteins 1 and 2 functionally interact with steroid hormone receptors to enhance their DNA binding in vitro and transcriptional activity in mammalian cells. Mol Cell Biol 1998; 18: 4471-4487.

24. Andersson U, Wang H, Palmblad K, Aveberger AC, Bloom O, Erlandsson-Harris H, Janson A, Kokkola R, Zhang M, Yang H, Tracey KJ. High mobility group 1 protein (HMG-1) stimulates proinflammatory cytokine synthesis in human monocytes. J Exp Med 2000; 192: 565-570.

25. Lotze MT, Tracey KJ. High-mobility group box 1 protein (HMGB1): nuclear weapon in the immune arsenal. Nat Rev Immunol 2005; 5: 331-342.

26. Shin YJ, Kim MS, Lee J, Kang M, Jeong JH. High-mobility group box 2 (HMGB2) modulates radio-response and is down-regulated by $\mathrm{p} 53$ in colorectal cancer cell. Cancer Biol Ther 2013; 14 (3): 213-221.

27. Ulloa L, Batliwalla FM, Andersson U, Gregersen PK, Tracey KJ. High mobility group box chromosomal protein 1 as a nuclear protein, cytokine, and potential therapeutic target in arthritis. Arthritis Rheum 2003; 48: 876-881.

28. Wang H, Yang H, Czura CJ, Sama AE, Tracey KJ. HMGB1 as a late mediator of lethal systemic inflammation. Am J Respir Crit Care Med 2001; 164: 1768-1773.

29. Ellerman JE, Brown CK, de Vera M, Zeh HJ, Billiar T, Rubartelli A, Lotze MT. Masquerader: High mobility group box-1 and cancer. Clin Cancer Res 2007; 13: 2836-2848.

30. Lange SS, Mitchell DL, Vasquez KM. High mobility group protein B1 enhances DNA repair and chromatin modification after DNA damage. PNAS 2008; 105 (30): 10320-10325.

31. Hreggvidsdóttir HS, Lundberg AM, Aveberger AC, Klevenvall L, Andersson U, Harris HE. High mobility group box protein 1 (HMGB1)partner molecule complexes enhance cytokine production by signaling through the partner molecule receptor. Mol Med 2012; 18: 224-230.

32. Bianchi ME, Agresti A. HMG proteins: dynamic players in gene regulation and differentiation. Curr Opin Genet Dev 2005; 15: 496-506

33. Agresti A, Bianchi ME. HMGB proteins and gene expression. Curr Opin Genet Dev 2003; 13: 170-178.
34. Tang D, Kang R, Zeh HJ, Lotze MT. High-mobility group box 1 and cancer. Biochim Biophys Acta 2010; 1799: 131-140.

35. Bolhassani A, Zahedifard F, Taghikhani M, Rafati S. Enhanced immunogenicity of HPV16E7 accompanied by Gp96 as an adjuvant in two vaccination strategies. Vaccine 2008; 26 (26): 3362-3370.

36. Bosch FX, Manos MM, Muñoz N, Sherman M, Jansen AM, Peto J, Schiffman MH, Moreno V, Kurman R, Shah KV. Prevalence of human papillomavirus in cervical cancer: a worldwide perspective. J Natl Cancer Inst 1995; 87 (11): 796-802.

37. Schwarz E, Freese UK, Gissmann L, MayerW, Roggenbuck B, Stremlau A, zur Hausen H. Structure and transcription of human papillomavirus sequences in cervical carcinoma cells. Nature 1985; 314 (6006): 111-114.

38. von Knebel Doeberitz M, Oltersdorf T, Schwarz E, Gissmann L. Correlation of modified human papillomavirus early gene expression with altered growth properties in C4-1 cervical carcinoma cells. Cancer Res 1988; 48 (13): 3780-3786.

39. Kim TK, Eberwine JH. Mammalian cell transfection: the present and the future. Anal Bioanal Chem 2010; 397 (8): 3173-3178.

40. Yang Y, Ma H. Western blotting and ELISA techniques. Researcher 2009; 1 (2): 67-86.

41. Mahmood T, Yang PC. Western Blot: Technique, theory and trouble shooting. N Am J Med Sci 2012; 4 (9): 429-34.

42. Kapadiya GM, Parmar AM, Sen DJ. Western blotting: An unique technology for detection of proteins by antigen-antibody interaction. World J Pharm Pharmaceut Sci 2014; 3 (10): 1810-1824.

43. Armstrong DJ, Roman A. The anomalous electrophoretic behavior of the human papillomavirus type $16 \mathrm{E} 7$ protein is due to the high content of acidic amino acid residues. Biochem Biophys Res Commun 1993; 192: $1380-1387$.

44. Kim TY, Myoung HJ, Kim JH, Moon IS, Ahn WS, Sin JI. Both $\mathrm{E} 7$ and $\mathrm{CpG}$-oligodeoxynucleotide are required for protective immunity against challenge with human papillomavirus 16 (E6/E7) immortalized tumor cells: involvement of $\mathrm{CD} 4+$ and $\mathrm{CD} 8+\mathrm{T}$ cells in protection. Cancer Res 2002; 62: 7234-7240.

45. Combs CA. Fluorescence microscopy: A concise guide to current imaging methods. Curr Protoc Neurosci 2010.

46. Ishikawa-Ankerhold HC, Ankerhold R, Drummen GPC. Advanced fluorescence microscopy techniques-FRAP, FLIP, FLAP, FRET and FLIM. Molecules 2012; 17 (4): 4047-4132.

47. Khan KH. Gene expression in mammalian cells and its applications Adv Pharm Bull 2013; 3 (2): 257-263.

48. Brown M, Wittwer C. Flow cytometry: Principles and clinical applications in hematology. Clin Chem 2000; 46: 1221-1229.

49. Cho SH, Godin JM, Chen CH, Qiao W, Lee H, Lo YH. Recent advancements in optofluidic flow cytometer. Biomicrofluidics 2010; 4 (4): 43001.

50. Müller S, Davey H. Recent advances in the analysis of individual microbial cells. Cytometry A 2009; 75 (2): 83-85.

51. Ambriz-Aviña V, Contreras-Garduño JA, Pedraza-Reyes M. Applications of flow cytometry to characterize bacterial physiological responses. BioMed Res Internat 2014; 1-14.

Received April 9, 2016. Accepted May 6, 2016. 